\title{
Group Work
}

Kristy J. Wilson, ${ }^{\dagger}$ Peggy Brickman, ${ }^{\ddagger}$ and Cynthia J. Brame ${ }^{\S *}$

'Biology Department, College of Arts and Sciences, Marian University, Indianapolis, IN 46222; "Department of Plant Biology, University of Georgia, Athens, GA 30602; 'Center for Teaching and Department of Biological Sciences, Vanderbilt University, Nashville, TN 37203

\begin{abstract}
Science, technology, engineering, and mathematics faculty are increasingly incorporating both formal and informal group work in their courses. Implementing group work can be improved by an understanding of the extensive body of educational research studies on this topic. This essay describes an online, evidence-based teaching guide published by CBE-Life Sciences Education (LSE). The guide provides a tour of research studies and resources related to group work (including many articles from LSE). Instructors who are new to group work, as well as instructors who have experienced difficulties in implementing group work, may value the condensed summaries of key research findings. These summaries are organized by teaching challenges, and actionable advice is provided in a checklist for instructors. Education researchers may value the inclusion of empirical studies, key reviews, and meta-analyses of group-work studies. In addition to describing key features of the guide, this essay also identifies areas in which further empirical studies are warranted.
\end{abstract}

\section{INTRODUCTION}

Group work is one of the most widely used and deeply researched teaching approaches in the college classroom. Group work that promotes students' collaboration to achieve shared learning goals has been shown to increase student achievement, persistence, and attitudes toward science (e.g., Springer et al., 1999; Tanner et al., 2003; Johnson and Johnson, 2009; Johnson et al., 2014). It can provide opportunities for students to explain their reasoning to one another and to themselves, thereby promoting the cognitive restructuring that leads to learning (e.g., Kagan, 2014). It offers opportunities for formative assessment and feedback with peers to shape that learning (e.g., Johnson and Johnson, 2009). It also provides students with an avenue to incorporate diverse viewpoints and to develop communication and teamwork skills that are especially important in scientific collaboration and professional fields (e.g., Lamm et al., 2012).

However, anyone who has worked in a group or used group work in courses has experienced challenges. These challenges, if left unchecked, can prevent effective learning and result in poor-quality products, unequal distribution of workload, and escalating conflict among team members (e.g., Feichtner and Davis, 1984). In this article, we describe an evidence-based teaching guide that we have created to condense, summarize, and provide actionable advice from research findings (including many articles from CBE-Life Sciences Education $[L S E])$. The guide can be found on the American Society for Cell Biology website (https://lse.ascb.org/evidence -based-teaching-guides/group-work), and a link will be listed on the LSE home page to direct users to a complete list of guides as this feature grows. We have included several useful features in the guide: a landing page that indicates starting points for instructors (Figure 1), syntheses of observations from the literature (Figure 2), summaries of and links to selected papers (Figure 3), and an instructor checklist that details recommendations and points to consider. The guide is meant to aid instructors who are new to group work as well as instructors who have tried group work
CBE Life Sci Educ March 1, 2018 17:fe1 DOI:10.1187/cbe.17-12-0258

*Address correspondence to: Cynthia J. Brame (Cynthia.brameavanderbilt.edu).

(C) 2018 K. J. Wilson et al. CBE-Life Sciences Education (c) 2018 The American Society for Cell Biology. This article is distributed by The American Society for Cell Biology under license from the author(s). It is available to the public under an Attribution-Noncommercial-Share Alike 3.0 Unported Creative Commons License (http:// creativecommons.org/licenses/by-nc-sa/3.0). "ASCB®" and "The American Society for Cell Biology ${ }^{\circledR}$ " are registered trademarks of The American Society for Cell Biology. 


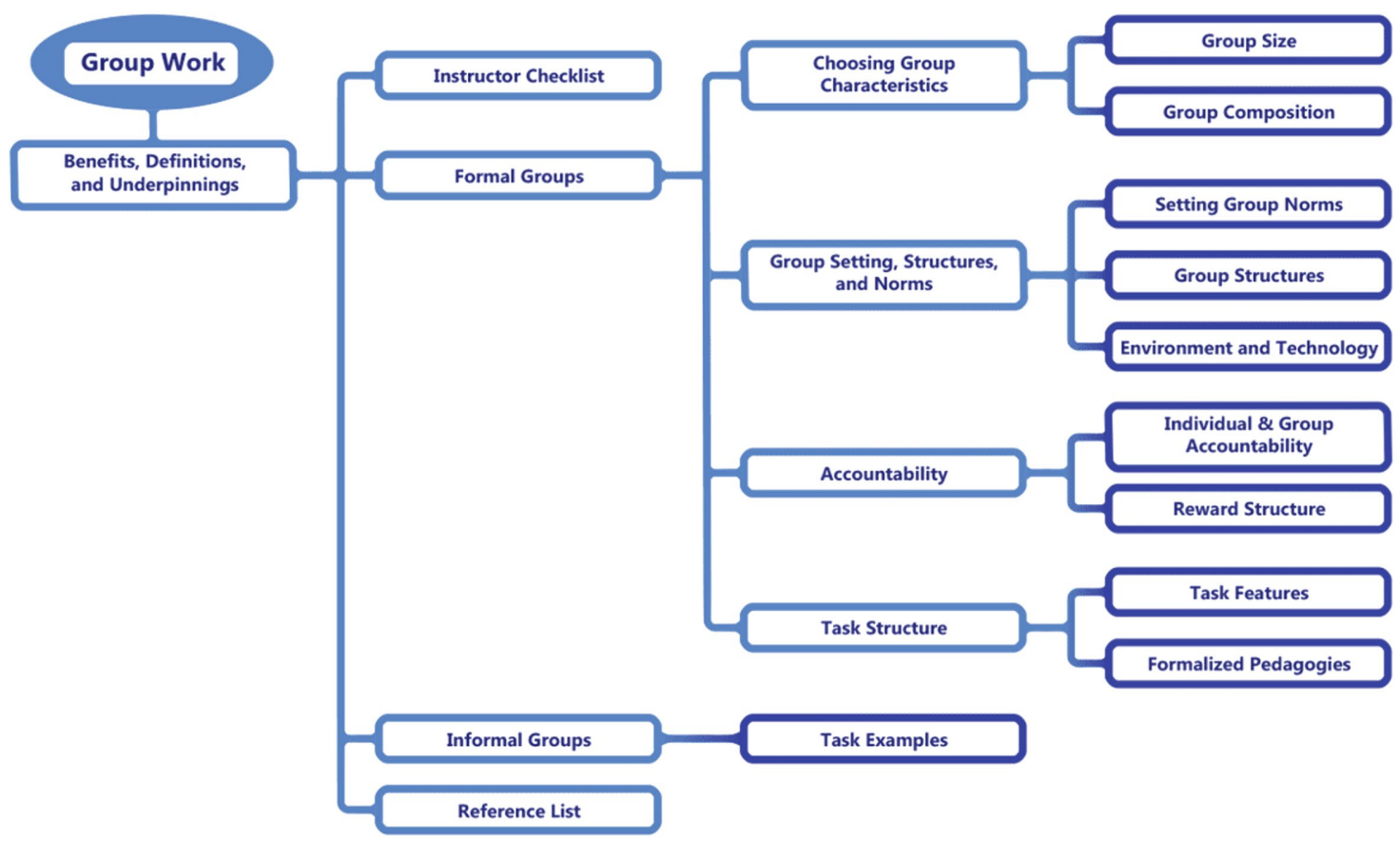

FIGURE 1. Screenshot representing the landing page of the guide, which provides readers with an overview of choice points.

and experienced difficulties or want to improve their students' experiences and outcomes. Researchers interested in exploring this area will also appreciate our efforts to identify empirical studies, informative reviews, and unanswered questions for which additional research is warranted. Some of the questions that we have considered in developing the guide are highlighted in the following sections.

\section{WHAT ARE THE BENEFITS OF FORMING PERMANENT VERSUS TEMPORARY GROUPS?}

The guide begins by separating findings, recommendations, and resources for formal, permanent groups from informal, temporary groups. During formal group work, students work in persistent groups for an extended period on a collaborative project, while in informal group work, ad hoc groups work

\section{Group Setting, Structures, and Norms}

There are several practices that can help make groups function effectively. The instructor should provide an opportunity for students to discuss their expectations for group work and to set group norms, including methods and expectations for communication, dealing with group members who don't contribute, and dealing with conflict within the group. In addition, the instructor should provide structure that promotes interdependence. This can be accomplished by structuring tasks that require contributions from all group members for completion —often with group members playing different roles-and establishing a reward structure that includes both individual and group components. For group work that spans multiple days or weeks, providing opportunities for peer evaluation can a means for ongoing adjustments to group interactions as well as a tool to promote individual accountability. Finally, it is important to consider the physical environment, including available technology, making choices about physical interactions and technology use that promote collaboration.

+ Setting Group Norms

- Group Structures

- Structured interdependence in group work requires that students communicate to promote each other's learning. By structuring groups to include this interdependence, students will be able to both help their peers and be helped themselves. This can lead to higher performance by the group itself and the individual members. One way to structure interdependence is assign or have students select particular roles to play within the group. If each of these roles is essential for task completion, students will necessarily depend on each other, promoting cooperation.

FIGURE 2. Screenshot showing an example description of overall conclusions that can be drawn about an element of group work, based on a synthesis of the literature. 


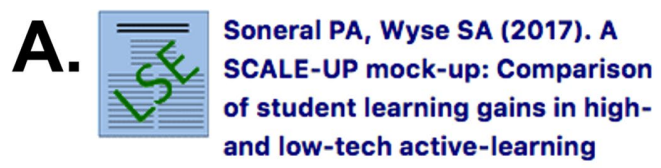

environments. LSE 16: ar12. Sonerel and

Wise compared a specifically designed and technologically sophisticated SCALE-UP classroom to a more inexpensive and low-tech Mock-Up classroom to determine what classroom features impact student performance and attitudes. Student performance was equivalent or better in the Mock-Up classroom compared to the SCALEUP Classroom. Students perceived that group interaction and whiteboards enhanced their learning. In contrast students rated the technology as less important. The paper suggests practical ways to adapt current classrooms to set the stage for collaborative and active learning.

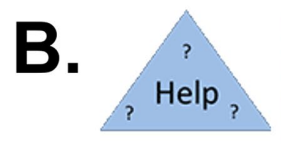

National Center for Case Based Teaching in Science (NCCTS) Contains peerreviewed cases, teaching notes, and answer keys covering a broad range of scientific topics that are searchable by subject and education level. The teaching resource section also has links to essays about different case structures, teaching with cases, and writing cases.

FIGURE 3. Screenshots representing (A) summaries and links to important papers and (B) other resources.

together on an in-class problem or question for periods ranging from a few minutes to a full class session (Johnson et al., 2014). Formal group work requires more planning and coordination, but the benefits are that it can help students work together to reach important course objectives. Informal group work, on the other hand, is easy to incorporate into classes of any size and in any space. Informal group work can be an effective supplement to lecture, allowing learners to process information, and is often an essential part of, or used in conjunction with, classic active-learning techniques (e.g., Tanner et al., 2003).

Three elements that are particularly important to consider in structuring formal group work are task interdependence, individual accountability, and reward interdependence (Johnson and Johnson, 2009). Task interdependence refers to the degree to which group members must work together to complete the assigned task. For optimal group benefit and motivation, tasks should not be able to be completed by just one or two group members, but rather should require contributions from all group members (e.g., Gillies, 2013). Individ- ual accountability, or the understanding that group members will be responsible for the work they specifically contribute, reduces social free-riding in group settings and encourages members to contribute. Reward interdependence can be accomplished through several mechanisms, including shared grades, for which individual students earn a final grade that relies on scores earned by their team members on a test or assignment, or certificates of recognition that students can earn if their average team scores on quizzes or other individual assignments exceed a pre-established criterion (Serrano and Pons, 2007).

Notably, the very distinction between the types of group work points to an unanswered research question:

Are there specific types of outcomes that are better met with informal group work rather than formal group work, or vice versa?

\section{SHOULD INSTRUCTORS FORM GROUPS OR LET STUDENTS SELF-SELECT THEIR OWN GROUPS?}

When planning formal group work, the literature suggests that instructors should form small groups (typically three to five students), considering student characteristics that can contribute to effective group processes and performance (e.g., Treen et al., 2016; and other references within the Group Size section of the guide). Generally, groups that are gender balanced, are ethnically diverse, and have members with different problem-solving approaches have been shown to exhibit enhanced collaboration (see references within the Group Composition section of the guide). Within these generic observations, however, there are a number of unanswered questions for which further research is needed:

- What are the different impacts for ethnic majority and minority students in ethnically diverse groups? If so, what are they, and why do they occur?

- Does context determine effective gender composition for groups? If so, is it a generalizable context (e.g., physics groups work best with one composition, while biology groups work best with another composition)? Alternatively, does the effectiveness of different group gender compositions depend on the measure being used (e.g., creativity of final product, effectiveness of group communication)? Are there task features or group structures that can mitigate disadvantages of particular gender mixes?

- The data on academic performance as a diversity factor also do not point to a single conclusion. What features of group work lead to benefits for high-, mid-, or low-performing students? Will these features be combined to benefit mixed-ability groups? Do homogeneous or heterogeneous groups provide a greater advantage?

- What are effective steps to take to support students with different disabilities while they participate in group work?

\section{WHAT CAN INSTRUCTORS DO TO PROMOTE QUALITY GROUP EXPERIENCES?}

There are a number of common problems that students and instructors experience when involved in group work. The most commonly reported problem is uneven workload 
(free-riding or overbearing students). However, groups also experience other types of social conflict and lack of cohesion that can result in production of "Frankenstein products" that are a conglomeration of individual student efforts without integration and synthesis of ideas. There are several practices and resources that can help ensure that groups function more effectively. Students report greater satisfaction with group work if the instructor has implemented methods to monitor and manage groups (Chapman and Van Auken, 2001; and other references within Setting Group Norms). Suggested methods include providing an opportunity for students to discuss their expectations for group work and setting group norms. For group work that spans multiple days or weeks, providing opportunities for identifying individual effort and allowing students to evaluate their peers can allow for ongoing adjustments to group dynamics. Assigning specific roles to students within groups can emphasize interdependence, and prompting students to provide elaborated explanations during discussions can help promote learning gains (Gillies, 2013). Even with these recommendations, there are many unanswered questions.

- Findings from research studies on peer evaluation have clearly identified several methods to identify dysfunctional groups. What are the potential solutions to address dysfunctional groups and under what conditions are these solutions effective? When is it more effective to disband a dysfunctional group rather than enforce mediation?

- What is the best method to deal with persistent free-riders?

\section{WHAT TASKS ARE IDEAL FOR PROMOTING EFFECTIVE GROUP WORK?}

We describe a number of formalized group-work pedagogies with defined criteria and tasks that instructors can consider. These include problem-based learning, team-based learning, process-oriented guided inquiry learning, case-based learning, and peer-led team learning, all of which have descriptions and biology-relevant papers linked within the Formalized Pedagogies section of the guide. Instructors considering these approaches should consider forming a team of instructors, administrators, and/or staff to address the attendant time and resource needs. For any group task, it is important to consider why group work is being used in a particular situation and how it meets the instructor's learning goals for students. To help promote student buy-in and student learning, these goals should be shared with students, along with an explanation of how the group work aligns with these goals.

Effective group tasks should challenge groups to solve highly complex or ill-structured problems that require the collaboration of the group to solve (e.g., Scager et al., 2016; and other references within the Task Features section). In addition, tasks that engage student interest, such as by using contemporary issues relevant to students' lives and generating products for an audience outside the classroom, can increase students' motivation (e.g., Schmidt et al., 2011). With this general recommendation in mind, however, there are a number of unanswered questions:

- Typically, a task's relevance to students' lives increases task value and thus student motivation. What are the best ways to structure relevant tasks in the biology classroom? Do these features differ by major or level of student?

- Does a students-as-producers approach, wherein students generate new knowledge for an external audience, impact motivation for all students or only some? Does the relative size of the product/student contribution matter (e.g., one figure on a poster vs. entire infographic for congressional representative)?

- How do different group tasks or task instructions affect cognitive development of knowledge structures and their use? What tasks support development of declarative knowledge (what), procedural knowledge (how), and conceptual knowledge (when/why)?

- Students lie at various places along the novice-expert continuum. How do we match scaffolding to student needs?

\section{WHEN NOT TO USE GROUP WORK}

We finish this summary to our guide by cautioning that group work is not a panacea for learning. A great deal of research has defined the type of tasks for which group work is more effective than individual learning. Groups of students show greater gains than individual students for tasks that are complex and illdefined with multiple possible correct answers (Kirschner et al., 2011), but for simpler tasks that require recall, definitions, or looking up information, students exhibit greater gains when they work on their own. Thus, maximizing the benefits of group work requires that instructors attend to the learning goals they want their students to attain and, if applicable, the group-work structures that they put in place to help the students reach those goals.

\section{ACKNOWLEDGMENTS}

We thank William Pierce and Thea Clarke for their efforts in producing the Evidence-Based Teaching Guides website and the American Society for Cell Biology for hosting the site.

\section{REFERENCES}

Chapman, K. J., \& Van Auken, S. (2001). Creating positive group experiences: An examination of the role of the instructor on students' perceptions of group projects. Journal of Marketing Education, 23, 117-127.

Feichtner, S. B., \& Davis, E. A. (1984). Why some groups fail: A survey of students' experiences with learning groups. Journal of Management Education, 9, 58-73

Gillies, R. M. (2013). Structuring cooperative group work in classrooms. International Journal of Educational Research, 39, 35-49.

Johnson, D. W., \& Johnson, R. T. (2009). An educational psychology success story: Social interdependence theory and cooperative learning. Educational Researcher, 38, 365-379

Johnson, D. W., Johnson, R. T., \& Smith, K. A. (2014). Cooperative learning Improving university instruction by basing practice on validated theory. Journal on Excellence in College Teaching, 25, 85-118.

Kagan, S. (2014). Kagan structures, processing, and excellence in college teaching. Journal on Excellence in College Teaching, 25(3-4), 119138.

Kirschner, F., Paas, F., \& Kirschner, P. A. (2011). Task complexity as a driver for collaborative learning efficiency: The collective working-memory effect. Applied Cognitive Psychology, 25(4), 615-624.

Lamm, A. J., Shoulders, C., Roberts, T. G., Irani, T. A., Snyder, J. L., \& Brendemuhl, B. J. (2012). The influence of cognitive diversity on 
group problem solving strategy. Journal of Agricultural Education, 53 , $18-30$.

Scager, K., Boonstra, J., Peeters, T., Vulperhorst, J., \& Wiegant, F. (2016). Collaborative learning in higher education: Evoking positive interdependence. 15(4), ar69.

Schmidt, H. G., Rotgans, J. I., \& Yew, E. H. J. (2011). The process of problem-based learning: What works and why. Medical Education, 45, 792-806.

Serrano, J. M., \& Pons, R. M. (2007). Cooperative learning: We can also do it without task structure. Intercultural Education, 18(3), 215-230.
Springer, L., Stanne, M. E., \& Donovan, S. S. (1999). Effects of small-group learning in science, mathematics, engineering, and technology: A meta-analysis. Review of Educational Research, 69, 21-51.

Tanner, K., Chatman, L. S., \& Allen, D. (2003). Approaches to cell biology teaching: Cooperative learning in the science classroom-beyond students working in groups. Cell Biology Education, 2, 1-5.

Treen, E., Atanasova, C., Pitt, L., \& Johnson, M. (2016). Evidence from a large sample on the effects of group size and decision-making time on performance in a marketing simulation game. Journal of Marketing Education, $38,130-137$ 